\title{
Reduction in DNA Synthesis During Two-photon Microscopy of Intrinsic Reduced Nicotinamide Adenine Dinucleotide Fluorescence
}

\author{
Michael G. Nichols ${ }^{\star 1,2}$, Erin E. Barth ${ }^{2}$ and Jennifer A. Nichols ${ }^{3}$ \\ ${ }^{1}$ Department of Physics, Creighton University, Omaha, NE \\ ${ }^{2}$ Department of Biomedical Sciences, Creighton University, Omaha, NE \\ ${ }^{3}$ Department of Chemistry, Cornell University, Ithaca, NY
}

Received 5 August 2004; accepted 10 January 2005

\section{ABSTRACT}

Two-photon laser scanning microscopy (TPLSM) of endogenous reduced nicotinamide adenine dinucleotide $(\mathrm{NAD}(\mathbf{P}) \mathrm{H})$ provides important information regarding the cellular metabolic state. When imaging the punctate mitochondrial fluorescence originating from $\mathrm{NAD}(\mathrm{P}) \mathrm{H}$ in a rat basophilic leukemia (RBL) cell at low laser powers, no morphological changes are evident, and photobleaching is not observed when many images are taken. At higher powers, mitochondrial NAD(P)H fluorescence bleaches rapidly. To assess the limitations of this technique and to quantify the extent of photodamage, we have measured the effect of TPLSM on DNA synthesis. Although previous reports have indicated a threshold power for "safe" two-photon imaging, we find the laser power to be an insufficient indicator of photodamage. A more meaningful metric is a two-photon-absorbed dose that is proportional to the number of absorbed photon pairs. A temporary reduction of DNA synthesis in RBL cells occurs whenever a threshold dose of approximately $2 \times 10^{53}$ photon $\mathrm{cm}^{-4} \mathrm{~s}^{-1}$ is exceeded. This threshold is independent of laser intensity when imaging with average powers ranging from 5 to $17 \mathrm{~mW}$ at $740 \mathrm{~nm}$. Beyond this threshold, the extent of the reduction is intensity dependent. DNA synthesis returns to control levels after a recovery period of several hours.

\section{INTRODUCTION}

Multiphoton excitation of fluorescent species in living cells and tissues has been a remarkably successful technique for imaging a variety of indicators of cell function and physiological status (1-3). This imaging strategy uses short, intense pulses of near-infrared

\Posted on the website on 12 January 2005

*To whom correspondence should be addressed: Department of Physics, Creighton University, 2500 California Plaza, Omaha, NE 68178, USA. Fax: 402-280-2140; e-mail: mnichols@creighton.edu

Abbreviations: BrdU, 5'-bromo-2'-deoxyuridine; dUTP, deoxyuridine triphosphate; FCCP, $p$ trifluoromethoxyphenylhydrazone; FWHM, full width half maximum; GDD, group-delay dispersion; GM, GöppertMayer; NA, numerical aperture; $\mathrm{NAD}^{+}$, oxidized nicotinamide adenine dinucleotide; NADH, reduced nicotinamide adenine dinucleotide; NADPH, reduced nicotinamide adenine dinucleotide phosphate; $\mathrm{NAD}(\mathrm{P}) \mathrm{H}, \mathrm{NADH}$ and/or NADPH; PBS, phosphate-buffered saline; PMT, photomultiplier tube; RBL, rat basophilic leukemia; TdT, terminal transferase; TPLSM, two-photon laser scanning microscopy; UV, ultraviolet.

(C) 2005 American Society for Photobiology 0031-8655/05 light to induce optical transitions that would otherwise require ultraviolet (UV) illumination. Near-infrared light is clearly preferred to UV illumination when imaging living cells and tissues because it both penetrates deeper in turbid tissue and causes less photodamage than UV light. Some mammalian cells have recently been shown to be 12 orders of magnitude less sensitive to light of wavelength 760-1064 nm than that of $308 \mathrm{~nm}$ (4). The extremely low cytotoxicity of near-infrared light has permitted biological studies that would otherwise have been impossible with UV or violet light $(5,6)$.

Although the cytotoxic effects of UV illumination have been characterized extensively, relatively little is known regarding the mechanism or mechanisms of near-infrared photodamage induced by exposures typically encountered during two-photon microscopy. Nevertheless, valuable insights into near-infrared photodamage mechanisms have been provided by a variety of recent reports. Oehring et al. (7) have reported deformations in the organization of mitochondrial inner membranes resulting in impaired cell division of CHO-K1 cells with ultrashort $800 \mathrm{~nm}$ pulses at powers exceeding $2 \mathrm{~mW}$. Tirlapur et al. (8) have reported recently that massive oxidative stress leading to apoptosis can occur in PtK2 cells irradiated with $800 \mathrm{~nm}, 170$ fs laser pulses with average powers exceeding $7 \mathrm{~mW}$. On the other hand, Hockberger et al. (5), working at $1047 \mathrm{~nm}$, did not detect $\mathrm{H}_{2} \mathrm{O}_{2}$ production with laser powers as high as $20 \mathrm{~mW}$, and Squirrell et al. (6) were able to maintain hamster embryo viability under prolonged imaging at $1047 \mathrm{~nm}$ with $13 \mathrm{~mW}$ average laser power. Our own practical experience has also demonstrated that cytotoxicity is reduced substantially when excitation wavelengths greater than $780 \mathrm{~nm}$ are used, yet depending on the application, this is not always possible $(9,10)$. Despite these reports, the actual mechanisms for near-infrared photodamage have yet to be isolated, although many candidates, ranging from specific molecular absorbers to optical breakdown and even laser-induced plasma formation, have been suggested.

A particularly interesting application of two-photon microscopy is metabolic imaging, wherein mitochondrial energetics can be followed by imaging reduced nicotinamide adenine dinucleotide $(\mathrm{NADH})$, the primary electron donor to the respiratory chain and the reduced form of the NADH-oxidized nicotinamide adenine dinucleotide $\left(\mathrm{NAD}^{+}\right)$redox couple. A one-photon absorption band peaking at $340 \mathrm{~nm}$ is present in the reduced fluorescent form but not in the oxidized form. The two-photon excitation spectrum of aqueous $\mathrm{NADH}$ was measured by $\mathrm{Xu}$ et al. (2) who reported a maximum action cross section of approximately 0.01 GöppertMayer (GM) $\left(10^{-52} \mathrm{~cm}^{4} \mathrm{~s}\right.$ photon $\left.{ }^{-1}\right)$ at $680 \mathrm{~nm}$, decaying nearly 100 -fold as the wavelength is increased from 740 to $800 \mathrm{~nm}$. These 
measurements were repeated and extended by Kasischke et al. (11) who found that the action cross section was $0.09 \mathrm{GM}$ at $700 \mathrm{~nm}$, nearly 10 times greater than the initial report. Two-photon metabolic imaging of the hippocampus (11), pancreas (12), intact cornea (13) and heart (14) has already been demonstrated successfully. It is also possible to simultaneously excite $\mathrm{NAD}(\mathrm{P}) \mathrm{H}$ and a variety of photosensitive drugs, which target mitochondria, to observe the effect of the drug on mitochondrial function $(15,16)$.

Although NADH is advantageous because it is an endogenous fluorophore, it is well known that NADH has relatively poor photostability. UV photooxidation of NADH in oxygenated, buffered solutions has been shown to regenerate enzymatically active $\mathrm{NAD}^{+}$while producing $\mathrm{H}_{2} \mathrm{O}_{2}$ as well as a variety of intermediates capable of producing oxidative stress in living cells (17). More recently, Joubert et al. (18) used a novel fluorescence recovery technique and found that the recovery of enzymatically active $\mathrm{NAD}^{+}$ was dependent on the extent of initial NADH photolysis. At low levels of NADH photolysis in aqueous solution, the NADH could be restored completely with the addition of alcohol dehydrogenase, whereas only $85 \%$ could be recovered when $80 \%$ of the initial NADH pool was photolyzed. A similar recovery was also demonstrated after UV irradiation of isolated mitochondria.

To better characterize the effect of high-intensity near-infrared radiation on mammalian cells during metabolic imaging of $\mathrm{NAD}(\mathrm{P}) \mathrm{H}$, we have measured the degree to which DNA synthesis is inhibited following well-defined imaging protocols. After twophoton intrinsic fluorescence imaging of living rat basophilic leukemia (RBL) cells at $740 \mathrm{~nm}$, we quantified the dependence of the incorporation of 5'-bromo-2'-deoxyuridine (BrdU), a thymidine analog, on the laser power and illumination time. These two parameters were systematically varied, and the degree of DNA synthesis inhibition was assessed as a function of a proper twophoton dose that is proportional to the rate of two-photon excitation that a given fluorophore would experience. The justification for initially assuming that damage depends on two-photon absorption and not single-photon absorption will be discussed in detail. Given this assumption, we find that DNA synthesis is reduced relative to unirradiated control cells after a threshold dose has been exceeded but synthesis returns to control levels after a recovery period of 4-8 h. Although the reduction in DNA synthesis may be correlated with $\mathrm{NAD}(\mathrm{P}) \mathrm{H}$ photobleaching during two-photon laser scanning microscopy (TPLSM) at an average power of $17 \mathrm{~mW}$, inhibition of DNA synthesis also occurs at lower powers where $\mathrm{NAD}(\mathrm{P}) \mathrm{H}$ bleaching is not evident.

\section{MATERIALS AND METHODS}

Cell culture. RBL growth media was minimum essential medium (GibcoBRL, Grand Island, NY) containing 10\% fetal bovine serum and $10 \%$ newborn calf serum (Gibco-BRL). For a given experiment, RBL cells were plated at a density of $1.15 \times 10^{5}$ cells $/ \mathrm{mL}$ on glass coverslip-bottomed grid dishes (P35G-7-c-grid; MatTek, Ashland, MA) and allowed to adhere overnight.

Two-photon laser scanning microscopy. Adherent cells were exposed to intense near-infrared illumination using a multiphoton microscope (1024MP; BioRad Laboratories, Hercules, CA). A diode-pumped solidstate laser (Millennia V; Spectra-Physics, Mountain View, CA) pumped a femtosecond titanium:sapphire laser (Tsunami; Spectra-Physics) to produce a train of $75 \mathrm{fs}$ pulses at $81 \mathrm{MHz}$ at a wavelength of $740 \mathrm{~nm}$. The uncompensated pulse train was raster scanned through an Axiovert 135TV Microscope (Zeiss, Jena, Germany) using a Zeiss 40×/1.3 F-Fluar objective. The intense illumination produced simultaneous two-photon excitation that was inherently localized to a subfemtoliter focal volume. The fluorescence emitted from this volume was collected through the same objective and reflected by a dichroic mirror (670DCXR; Chroma Technology, Brattleboro, VT) placed in the Fourier plane of the microscope without descanning. The emitted $\mathrm{NAD}(\mathrm{P}) \mathrm{H}$ fluorescence signal was selected by a band-pass filter (HQ450/100) and detected with a photomultiplier tube (PMT) (HC120-01; Hamamatsu, Bridgewater, NJ). Experiments were conducted by independently varying both the average laser power and the number of fluorescence images collected from a single image plane approximately $2-4 \mu \mathrm{m}$ above the coverslip.

Calculation of the specific two-photon dose. We hypothesized that cellular photodamage resulting from TPLSM would be induced linearly with the number of absorbed photon pairs and defined the two-photonabsorbed dose as

$$
D_{2 v}=\langle N(t)\rangle T_{V} V .
$$

Where, $\langle N(t)\rangle$ is the time-averaged absorption rate, $T_{V}$ is the exposure time per unit volume and $V$ is the total exposed cellular volume. The timeaveraged absorption rate depends on the average concentration, $\mathrm{C}_{\mathrm{i}}$, and the two-photon-absorption cross section, $\sigma_{\mathrm{i}}$, of all absorbing species in the focal volume,

$$
\langle N(t)\rangle=\sum_{\mathrm{i}} \sigma_{\mathrm{i}} \mathrm{C}_{\mathrm{i}} \int\left\langle I^{2}(\vec{r}, t)\right\rangle d^{3} \vec{r}
$$

where $I$ is the time- and spatially-dependent intensity. Although we have an incomplete understanding of the relevant absorbers within the cell that are two-photon excited by ultrashort, near-infrared optical pulses, we can define a parameter, $\Delta$, that expresses the incident two-photon-specific dose to which any given molecular absorber would be subject,

$$
\Delta=T_{V} \int\left\langle I^{2}(\vec{r}, t)\right\rangle d^{3} \vec{r}
$$

With this identification,

$$
D_{2 v}=\Delta \sum_{\mathrm{i}} \sigma_{\mathrm{i}}\left(\mathrm{C}_{\mathrm{i}} V\right)
$$

and $\Delta$ is the dose per effective two-photon-absorption cross section. Given that the cross section is measured in units of $\mathrm{cm}^{4} \mathrm{~s}_{\text {photon }}{ }^{-1}$, this specific dose parameter has units of photon $\mathrm{cm}^{-4} \mathrm{~s}^{-1}$.

Following the treatment of Xu and Webb (19), we separated the intensity into spatial and temporal counterparts and used the second-order temporal coherence to obtain the average-squared intensity in terms of the more readily measured average intensity. This yields

$$
\Delta=\frac{g_{p}}{f \tau}\left\langle I_{0}(t)\right\rangle^{2} T_{V} \int S^{2}(\vec{r}) d^{3} \vec{r},
$$

where $g_{p}$ is a constant that depends on the temporal pulse profile, $f$ is the repetition rate of the laser, $\tau$ is the temporal pulse width at the sample, $S$ is the unit-normalized point-spread function (PSF) characteristic of the microscope objective and $I_{0}$ is the peak intensity generated at the focus of the high numerical aperture (NA) objective. We determined the pulse width at the sample from a measurement of the laser pulse width, $\tau_{\mathrm{L}}$, using the group-delay dispersion (GDD) measured according to the technique described by Guild et al. (20). Assuming third-order dispersion can be neglected, the pulse width at the sample will broaden from $\tau_{\mathrm{L}}$ to $\tau$ after traveling through an optical system with GDD of $\phi^{\prime \prime}$ according to the relation

$$
\tau=\tau_{\mathrm{L}}\left(1-\left(\frac{4 \ln 2 \phi^{\prime \prime}}{\tau_{\mathrm{L}}^{2}}\right)^{2}\right)^{0.5}
$$

In practice, the average power transmitted through the back aperture of the objective, $\langle P\rangle_{\mathrm{ba}}$, and the ratio of the radius of the back aperture, $a$, to the beam radius was measured. This ratio, $\beta$, describes the filling of the objective, with $\beta=0$ indicating a complete overfill. This parameter determines both the optical power delivered to the focus as well as the size of the focal spot (21). To compute the average intensity at focus, we followed the approach of Richards and Wolf (22), who derived a vectorial solution that is not limited to low-NA objectives. Given the index of refraction of the medium, $n$, the focal length, $l$, and measured fractional transmission of the objective, $\chi$, the average intensity at focus is given by 
Table 1. Imaging parameters influencing the two-photon-specific dose

\begin{tabular}{lccc}
\hline \multicolumn{1}{c}{ Parameter description } & Symbol & Value & Units \\
\hline Dispersion & $\phi^{\prime \prime}$ & 3300 & $\mathrm{fs}^{2}$ \\
Numerical aperture & $\mathrm{NA}$ & 1.30 & - \\
Index of refraction & $n$ & 1.33 & - \\
Objective back aperture radius & $a$ & 3.75 & $\mathrm{~mm}$ \\
Objective focal length & $l$ & 4.00 & $\mathrm{~mm}$ \\
Objective filling factor & $\beta$ & 2 & - \\
Temporal pulse shape factor & $g_{p}$ & 0.59 & - \\
Repetition rate & $f$ & 81 & $\mathrm{MHz}$ \\
Laser pulse width & $\tau_{\mathrm{L}}$ & $68-80$ & $\mathrm{fs}$ \\
Wavelength & $\lambda$ & 740 & $\mathrm{~nm}$ \\
Integrated PSF & & 0.0844 & $\mu \mathrm{m}^{3}$ \\
Single scan acquisition time & & 1.08 & $\mathrm{~s}$ \\
Scans averaged per image & & 3 & $\mathrm{~s}$ \\
Image acquisition time & $T_{\mathrm{S}}$ & 3.24 & $\mathrm{~s}$ \\
Fraction of time in image & $Q$ & 0.898 & - \\
Image pixel area & & 0.126 & $\mu \mathrm{m}^{2}$ \\
Image area (512 $\times$ 512 pixels) & $A$ & 33036 & $\mu \mathrm{m}^{2}$ \\
Depth of image plane (FWHM) & $\bar{z}$ & 0.868 & $\mu \mathrm{m}$ \\
\hline
\end{tabular}

$$
\left\langle I_{0}(t)\right\rangle=\frac{\langle P\rangle_{\mathrm{ba}} \chi}{\pi a^{2}}\left(\frac{2 \beta^{2}}{1-e^{-2 \beta^{2}}}\right)\left(\frac{n \pi l}{\lambda}\right)^{2}
$$

To calculate the exposure time per unit volume, we determined the time for a single image acquisition, $T_{\mathrm{s}}$, the fraction of the time the laser beam spends in the image field of view, $Q$, and the total illuminated volume in a single scan. This volume is the product of the area of the image, $A$, and the axial length of the two-photon point-spread function, $\bar{z}$. This results in the following expression for the average exposure time per unit volume,

$$
T_{V}=\frac{T_{\mathrm{S}} Q}{A \bar{z}} .
$$

Inserting Eqs. 7 and 8 into Eq. 3 yields the specific dose parameter in terms of the experimental imaging conditions used in this study,

$$
\Delta=\frac{g_{p}}{f \tau}\left(\frac{\pi n^{2}\langle P\rangle_{\mathrm{ba}}^{2} \chi^{2} l^{2}}{a^{2} \lambda^{2}}\right)\left(\frac{2 \beta^{2}}{1-e^{-2 \beta^{2}}}\right)^{2}\left(\frac{T_{\mathrm{S}} Q}{A \bar{z}}\right) \int S^{2}(\vec{r}) d^{3} \vec{r} .
$$

We performed numerical calculations of the normalized intensity distribution, $S(\vec{r})$, appropriate for a 1.3 NA objective with $\beta=2$ and found the integral in Eq. 9 to have a value of $0.0844 \mu \mathrm{m}^{3}$, with an axial length (full width half maximum [FWHM]) of $0.868 \mu \mathrm{m}$ (21). Table 1 summarizes the values of the parameters used to calculate the two-photonspecific dose parameter. From Eq. 9, the typical two-photon-specific doses used in this study are 4.36, 17.1 and $46.8 \times 10^{51}$ photon ${ }^{2} \mathrm{~cm}^{-4} \mathrm{~s}^{-1}$ per image for images acquired at average powers of 5,10 and $17 \mathrm{~mW}$ at the sample, respectively. The dose rate was calculated for each experiment on the basis of the measured average power and pulse width, which were varied from experiment to experiment.

Irradiation protocol. Before imaging, the growth medium was replaced with room-temperature phenol red-free imaging buffer $(135 \mathrm{~m} M \mathrm{NaCl}, 5 \mathrm{~m} M$ $\mathrm{KCl}, 1 \mathrm{~m} M \mathrm{MgCl}_{2}, 1.8 \mathrm{~m} M \mathrm{CaCl}_{2}, 20 \mathrm{~m} M N$-[2-hydroxyethyl]piperazine- $N^{\prime}$ [2-ethanesulphonic acid] (HEPES), $5 \mathrm{mM}$ D-glucose, $0.5 \%$ bovine serum albumin). Two-photon-excited intrinsic $\mathrm{NAD}(\mathrm{P}) \mathrm{H}$ fluorescence and transmitted light images were obtained for a number of irradiated regions on a dish. For each region, a reference laser power was measured and used to determine the average power at the sample. The autocorrelation pulse width was also measured. Typically, four to six individual regions, each containing approximately 20 cells, were imaged for each dish, depending on the time required to image a given region. Cells were exposed to imaging buffer for no longer than $1 \mathrm{~h}$ before the start of the DNA synthesis assay.

$D N A$ synthesis assay. The functional endpoint chosen to assess damage during multiphoton microscopy was the cell's ability to incorporate BrdU during DNA synthesis. A graphical depiction of this assay is shown in Fig. 1. Immediately after irradiation, the imaging buffer was aspirated from the dish and replaced with fresh growth medium. The dish was then placed in a $37^{\circ} \mathrm{C}$, $5 \% \mathrm{CO}_{2}$ incubator for a recovery period of $1 \mathrm{~h}$. After this time interval, the growth medium was replaced with growth medium containing $40 \mu M \mathrm{BrdU}$

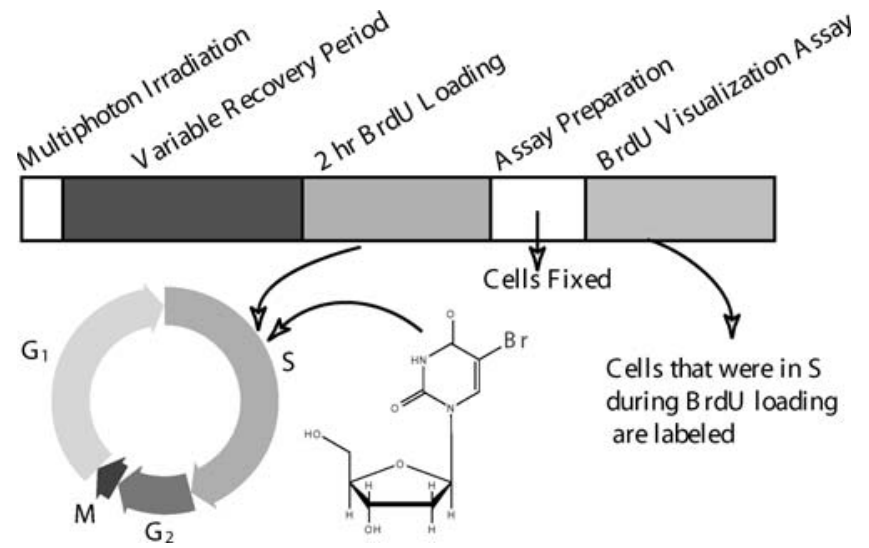

Figure 1. Schematic representation of the BrdU incorporation assay. Following a particular imaging protocol, cells were allowed a recovery period (typically $1 \mathrm{~h}$ ) to permit repair of photodamage resulting from imaging. Cells were then incubated with BrdU, which is taken up and incorporated into the DNA of cells that are going through synthesis. At this point, the cells were fixed and stained to fluorescein label those cells that incorporated $\mathrm{BrdU}$, following the technique of $\mathrm{Li}$ et al. (23). Previously imaged regions and control regions were then assayed by fluorescein-dUTP confocal microscopy to measure the uptake of BrdU and the fraction of cells going through DNA synthesis.

(Sigma-Aldrich, St. Louis, MO) and the dish was returned to the incubator for a period of $2 \mathrm{~h}$. Cells undergoing synthesis during this time incorporated the thymidine analog, BrdU, into their DNA. The medium was then replaced with fresh phenol red-free imaging media containing $37 \mu M$ Hoechst 33258 (Molecular Probes, Eugene, OR), and the dish was returned to the incubator for a period of $20 \mathrm{~min}$. During this interval Hoechst will bind to the minor groove of DNA in all cells. Cells were then rinsed with imaging media and exposed to $254 \mathrm{~nm}$ UV light with a handheld lamp (Spectroline; Krackeler Scientific, Durham, NC) for $10 \mathrm{~min}$. The combination of Hoechst 33258, $\mathrm{BrdU}$ and UV light is known to efficiently produce strand breaks at locations of BrdU incorporation, whereas nuclei that do not incorporate BrdU show a negligible level of strand breaks (23). Immediately after UV exposure, the cells were rinsed and fixed with a $4 \%$ paraformaldehyde solution in phosphate-buffered saline (PBS) ( $\mathrm{pH} 7.0$ ) for $30 \mathrm{~min}$ at room temperature. At this point, cells were either stored at $0^{\circ} \mathrm{C}$ with a small volume of methanol for up to 1 week or immediately stained to show BrdU incorporation by a terminal transferase (TdT) end-labeling assay.

Fluorescent labeling of exposed 3' DNA strands. After cold storage, the methanol was removed and the cells were washed once with PBS, rehydrated in PBS at room temperature for several minutes and then washed a third time. The cells were permeabilized with a $0.1 \%$ solution of cold Triton X-100 in PBS for $3 \mathrm{~min}$ at room temperature and washed three times with PBS. The $7 \mathrm{~mm}$ wells of the MatTek dishes were filled with $50 \mu \mathrm{L}$ TdT end-labeling solution (12.5 U TdT, $10 \mu M$ fluorescein-12-deoxyuridine triphosphate (dUTP), in $1 \times$ TdT reaction buffer with $2.5 \mathrm{~m} M$ cobalt chloride; Roche Diagnostics, Indianapolis, IN) and incubated at $37^{\circ} \mathrm{C}$ for $1 \mathrm{~h}$. Labeled dishes were washed and the antifade agent, Vectashield (Vector Labs, Burlingame, CA), was added to the wells before confocal imaging.

Confocal microscopy of fluorescein-dUTP-labeled nuclei. The incorporation of BrdU into cells after multiphoton microscopy was measured by confocal microscopy of the fluorescein-dUTP-labeled nuclei. Previously irradiated regions were relocated using the coverslip grid as a reference. Fluorescein-dUTP and nonspecific intrinsic fluorescence was excited using the $488 \mathrm{~nm}$ line of a krypton-argon laser and detected through a $515 \mathrm{~nm}$ long-pass filter (OG 515; Chroma Technology). As shown in Fig. 5, labeled nuclei had a characteristic ellipsoidal shape and a wide variety of labeling patterns that are typical of BrdU incorporation (23). In contrast, the unlabeled cells had a uniform intrinsic fluorescence throughout the cell body. The laser power and PMT gain were adjusted so that both the brightest fluorescein-labeled nuclei and the dimmest nonspecific intrinsic fluorescence from unlabeled cells could be observed. Nuclei were scored according to the average pixel intensity within the nuclear region when it could be discerned or the average intensity of the cell body when it could 
Figure 2. Two-photon-excited NAD $(\mathrm{P}) \mathrm{H}$ fluorescence of RBL cells is dependent on the energy state of the mitochondria. (A) Punctate fluorescence of mitochondrial $\mathrm{NAD}(\mathrm{P}) \mathrm{H}$ with a lower intensity diffuse cytosolic background. (B) Sodium cyanide incubation ( $1 \mu M$ for $15 \mathrm{~min}$ ) increases intrinsic mitochondrial fluorescence nearly three-fold because oxygen is no longer able to accept reducing equivalents from NADH. (C) Uncoupling the mitochondria with $1 \mu M$ FCCP for $15 \mathrm{~min}$ causes a rapid transfer of reducing equivalents, leaving the mitochondria depleted of $\mathrm{NAD}(\mathrm{P}) \mathrm{H}$.
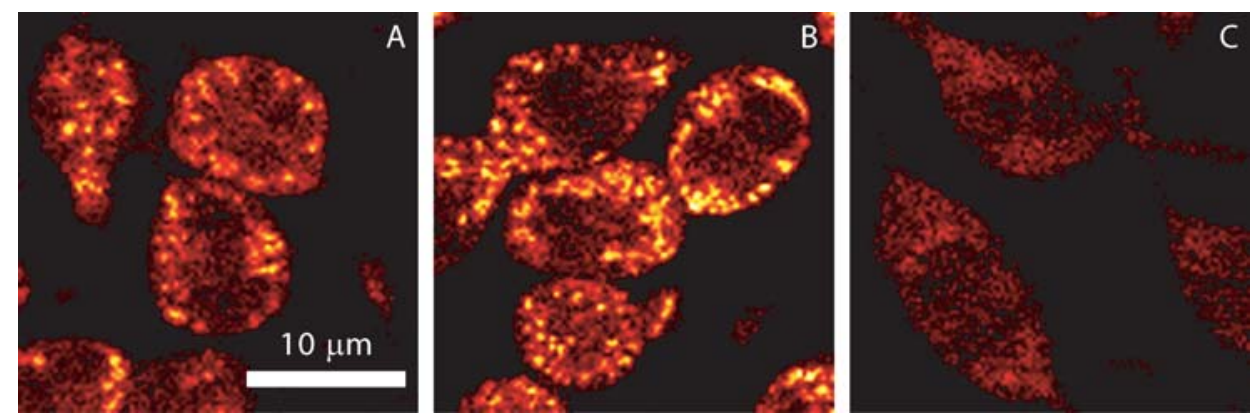

not. Histograms of nuclei intensity were compiled for cells that were treated with the same irradiation dose, as shown in Fig. 6.

Generally, the histograms appeared bimodal, making it possible to separate cells that entered synthesis at some point during the BrdU loading period from cells that did not. The narrow, low-intensity peak is because of nonspecific fluorescence. Only this peak remains if BrdU is omitted from the assay altogether (data not shown). In contrast, the broad distribution represents cells that incorporated some amount of BrdU during the assay. The wide intensity range reflects the unsynchronized character of the cell population. In addition to the irradiated regions, results from several controls were also compiled. Unirradiated regions adjacent to irradiated regions were assayed to provide an unirradiated control for each dish. The imaging buffer used did not appear to have any measurable effect on the experiment because intensity histograms of cells that were not washed in imaging buffer or brought to room temperature were equivalent to the experimental controls.

Test of false-positive artifacts. Because BrdU incorporation is assayed by labeled DNA strand breaks, it is conceivable that photodamage resulting in such breaks could provide a false-positive indication of BrdU incorporation. There is a substantial literature indicating either direct or indirect strand breaks caused by intense near-infrared illumination of mammalian cells (see, for example, Mohanty et al. [4]; Shafirovich et al. [24] and references therein). Furthermore, cells spontaneously undergoing apoptosis could also lead to a false-positive artifact. To check for these possibilities, control dishes were treated using the same irradiation protocol as the experiment dishes, but during the DNA synthesis assay, the step involving the addition of BrdU was omitted, i.e. (-) BrdU control. Both irradiated and nonirradiated (-) BrdU controls indicated a consistent level of approximately 2-3\% apoptotic cells. The fact that this level appeared to be independent of the irradiation intensity and exposure leads to the conclusion that the frequency of strand breaks caused by near-infrared illumination was insufficient to lead to a falsepositive artifact. Hence, BrdU incorporation can safely be inferred by fluorescein-dUTP-labeled nuclei for this study.

Data analysis. Cell histograms such as those in Fig. 6 were analyzed to determine the fraction of cells entering synthesis during the BrdU assay and the fluorescein-dUTP nuclear staining intensity. The fraction of cells entering synthesis was determined by dividing the number of cells with nuclear fluorescence intensity greater than the (-) BrdU control group by the total number of cells in the individual experiment. To account for electronic offset and fixation fluorescence, the mean nuclear fluorescence intensity was determined by subtracting the greatest fluorescence intensity found in the (-) BrdU group from the average nuclear fluorescence of nuclei with fluorescence intensity greater than the $(-)$ BrdU group. The histograms obtained from the unirradiated control cells were analyzed in the same manner. Data from scanned regions were normalized to the data from control regions and the weighted means as well as the error in the weighted means were calculated for all replicate experiments conducted with the same irradiation protocol (25).

\section{RESULTS}

\section{Metabolic imaging by TPLSM of NAD(P)H}

TPLSM of mitochondrial NAD(P)H has been used previously to indicate the metabolic status of living cells (11-16). Figure 2 shows the effects of mitochondrial inhibitors and uncouplers on the intrinsic $\mathrm{NAD}(\mathrm{P}) \mathrm{H}$ fluorescence of RBL cells. The normal, punctate distribution of fluorescence, shown in Fig. 2A, originated primarily from mitochondria with a less intense diffuse NAD(P)H signal from the cytosol. This was verified both by microspectrophotometry and by observing the colocalization of $\mathrm{NAD}(\mathrm{P}) \mathrm{H}$ fluorescence with Mitotracker Red (Molecular Probes, Eugene, OR) using TPLSM (data not shown). Incubation of $1 \mu M$ sodium cyanide prevented the transfer of reducing equivalents from NADH to the respiratory chain resulting in an increase in NADH (Fig. 2B), whereas uncoupling electron transport from oxidative phosphorylation with $1 \mu M$ of the proton ionophore trifluoromethoxyphenylhydrazone (FCCP) resulted in the rapid conversion of NADH to the nonfluorescent oxidized form, $\mathrm{NAD}^{+}$(Fig. 2C). A quantitative comparison of the normal, maximally reduced and maximally oxidized NADH fluorescence intensities of approximately 80 individual cells indicated that under these imaging conditions RBL cells are only $18.5 \%$ reduced (data not shown).

\section{Cellular NAD(P)H photobleaching during TPLSM}

Images in Fig. 2 were taken at $740 \mathrm{~nm}$ with a relatively high average laser power of $17 \mathrm{~mW}$ at the sample. Although the good $\mathrm{NAD}(\mathrm{P}) \mathrm{H}$ fluorescence signal clearly allowed individual mitochondria to be observed, a rapid fading because of the high laser power did not permit an extended study of this group of cells. This is evident from the lack of mitochondrial $\mathrm{NAD}(\mathrm{P}) \mathrm{H}$ fluorescence after just 25 images, as shown in Fig. 3B. Figure 3C reveals an approximately exponential decay of the fluorescence intensity for three of the cells. In each case, only the bright, punctate fluorescence comprising approximately $30 \%$ of the total cellular fluorescence from this plane decayed in the first 11 images. In contrast, the background fluorescence level remained fairly constant for the final 14 images. Lowering the average laser power at the sample to $10 \mathrm{~mW}$ (Fig. 4A-C) prevented the loss of signal while maintaining sufficient, albeit reduced, signal-to-noise ratio to resolve persistent mitochondrial patterns.

It is worthwhile noting that the cells in Fig. 3B closely resemble cells with uncoupled mitochondria (Fig. 2C). The decay shown in Fig. 3C, and others similar to it, progressed with each scan. The $\mathrm{NAD}(\mathrm{P}) \mathrm{H}$ fluorescence intensity remained constant when a prolonged dark period was inserted between scans, neither recovering nor continuing to decay in the absence of illumination. Finally, we also simultaneously two-photon excited $\mathrm{NAD}(\mathrm{P}) \mathrm{H}$ and rhodamine 123 in RBL cells at this wavelength and did not observe a leakage of rhodamine 123 into the cytosol, which would have indicated a loss of mitochondrial membrane potential (15).

\section{Reduction of DNA synthesis activity after TPLSM}

To determine the effect of the laser power and the number of images acquired on the health of the cell, BrdU incorporation was 

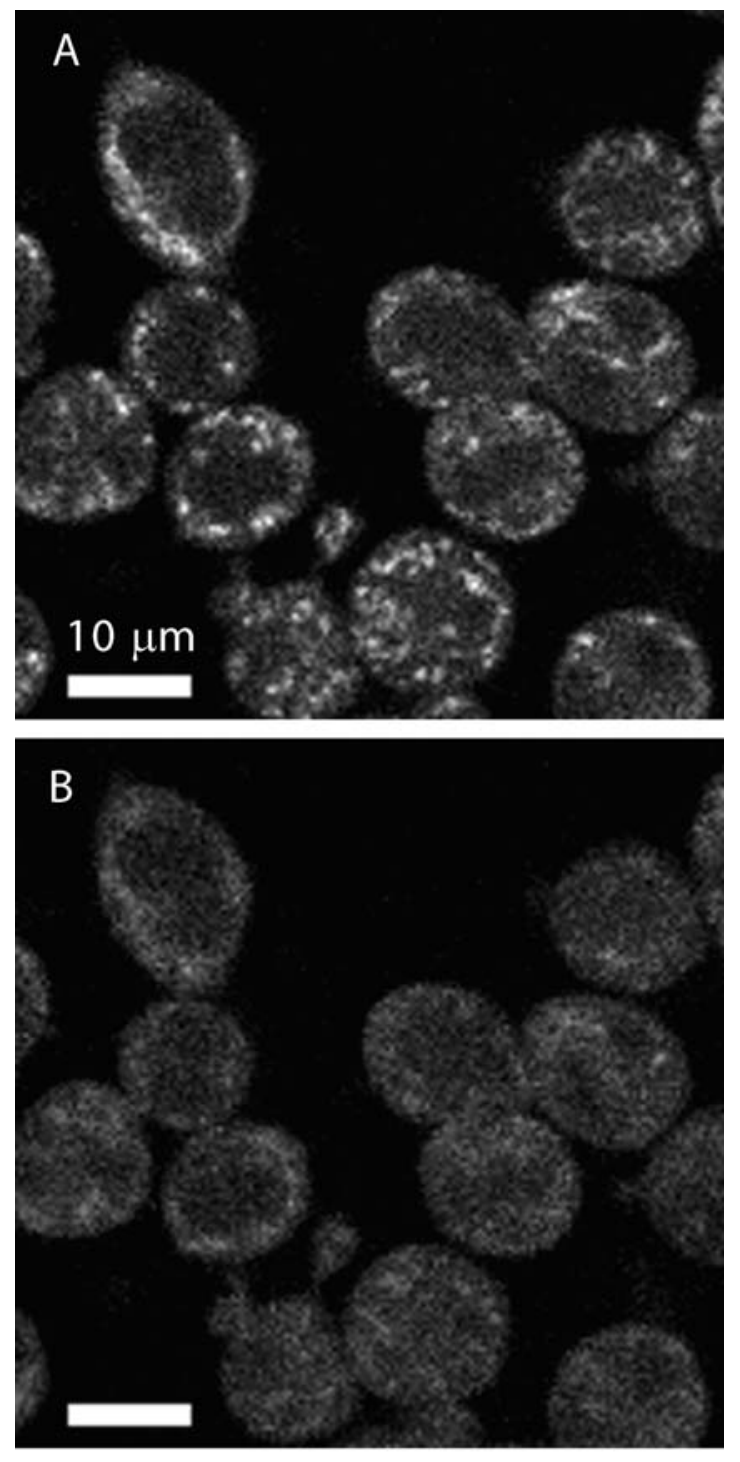

C

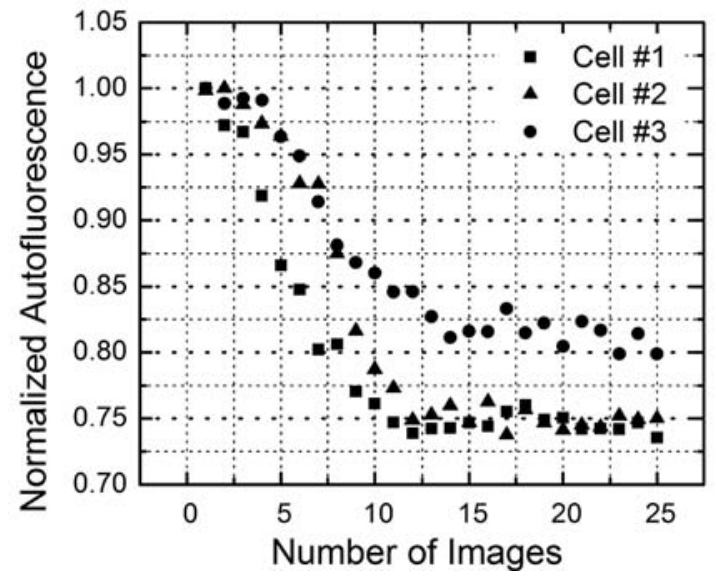

Figure 3. The effects of repetitive TPLSM of RBL cells using high (17 $\mathrm{mW}$ ) laser power. (A) Initial $\mathrm{NAD}(\mathrm{P}) \mathrm{H}$ fluorescence image. (B) 25th image. (C) The normalized fluorescence signal for three representative cells in $A$.
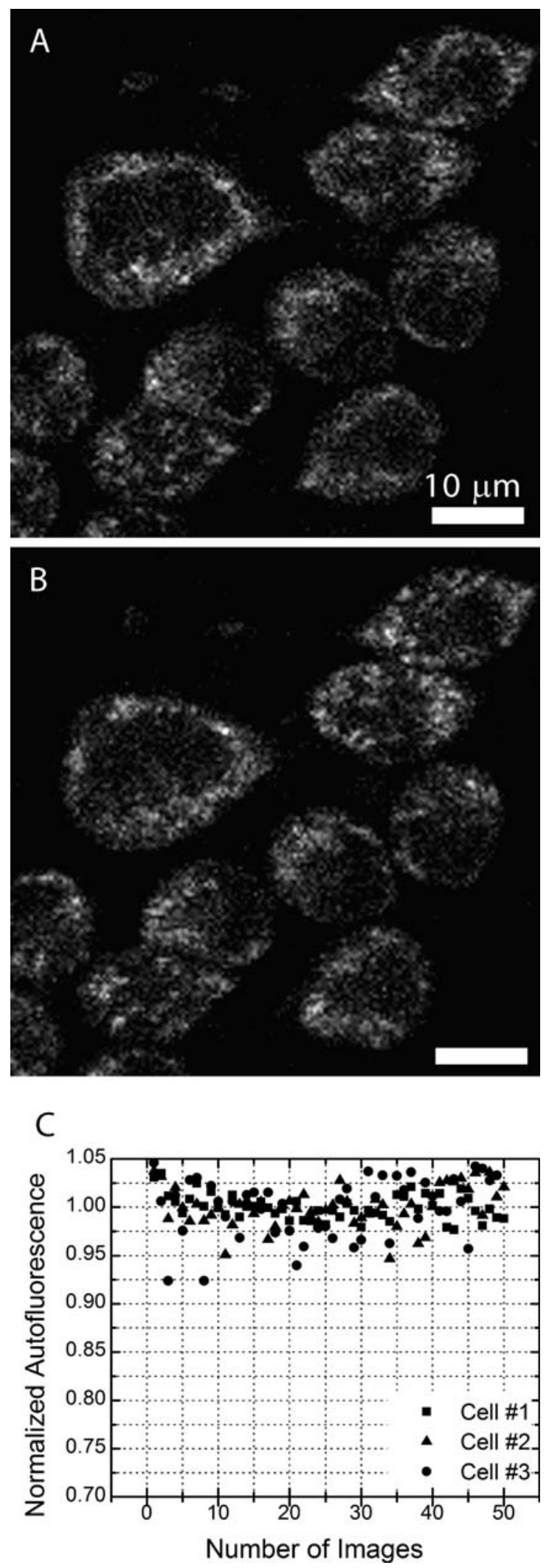

Figure 4. The effects of repetitive TPLSM of RBL cells using low (10 $\mathrm{mW}$ ) laser power. (A) Initial $\mathrm{NAD}(\mathrm{P}) \mathrm{H}$ fluorescence image. (B) 50th image. (C) The normalized fluorescence signal for three representative cells in $A$. 

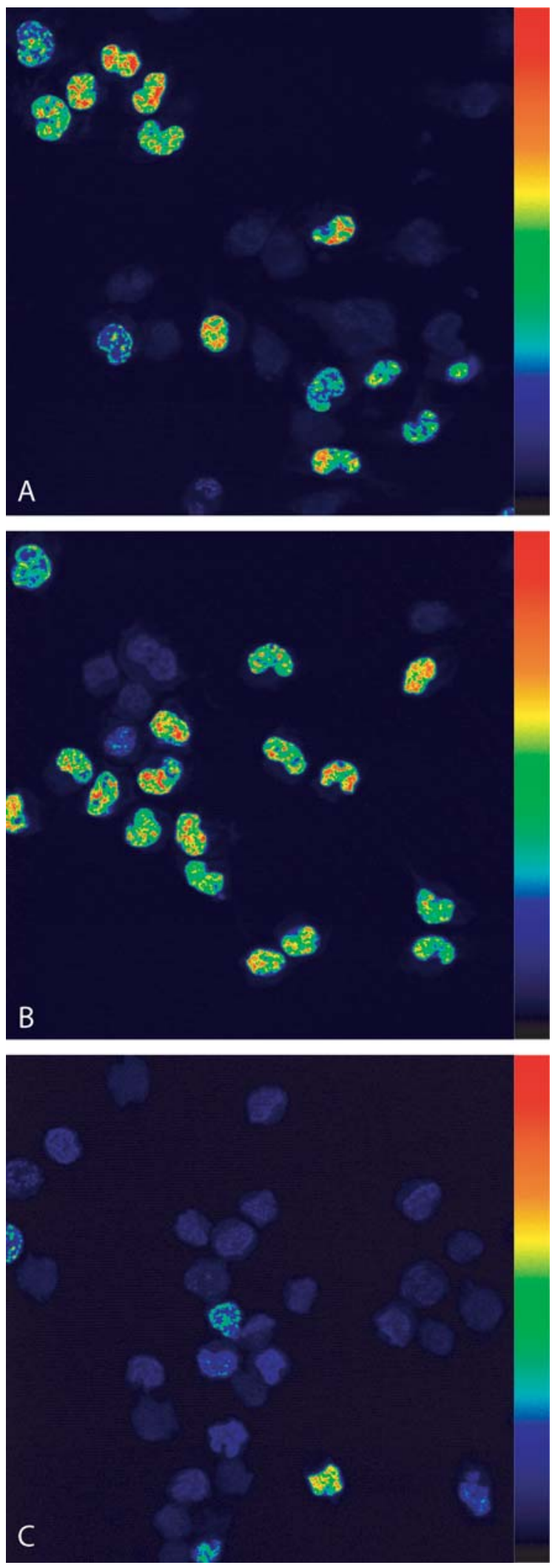

Figure 5. Fluorescein-dUTP confocal images of unsynchronized RBL cells that have been labeled after the BrdU incorporation assay. All three images use the same intensity scale to show the relative incorporation of BrdU into the nucleus. Cells with red nuclei incorporated more BrdU than cells with blue nuclei. (A) Control RBL cells that have not been exposed to quantified as a function of the average laser power at the sample and the number of images acquired. An example of the alteration in the level of BrdU incorporation during imaging at 10 and $17 \mathrm{~mW}$ is shown in Fig. 5. Because the cell population was unsynchronized and BrdU loading was limited to a $2 \mathrm{~h}$ interval, $55 \%$ of control cells (Fig. 5A) typically had brightly stained nuclei whereas the rest showed a very low background. Variation in the staining intensity and distribution within the nucleus reflects both the time spent in synthesis as well as the replication sequence. Nevertheless, nuclear fluorescence increases monotonically with increasing synthesis. Two-photon metabolic imaging with an average power of $10 \mathrm{~mW}$ (five images), yielding a specific dose of $9.1 \times 10^{52}$ photon $^{2} \mathrm{~cm}^{-4}$ $\mathrm{s}^{-1}$, resulted in a level of BrdU incorporation that is unchanged from unirradiated controls (Fig. 5B). But cells imaged at a greater two-photon-specific dose of $1.2 \times 10^{54}$ photon $^{2} \mathrm{~cm}^{-4} \mathrm{~s}^{-1}(17 \mathrm{~mW}$ for 25 images) showed a sharp decline in the nuclear staining intensity (Fig. 5C).

Experiments such as these were repeated at several locations in a given dish for several dishes, and histograms of the distribution of nuclear fluorescence intensities were compiled for quantitative analysis. Representative histograms from cells on three separate dishes are shown in Fig. 6. Figure 6A shows a histogram from unirradiated control cells such as those in Fig. 5A, whereas the histograms in Fig. 6B,C were derived from irradiated cells such as those in Fig. 5B,C, respectively. In these histograms, the dark bars represent unlabeled cells having mean nuclear fluorescence of less than 20 arbitrary units. The same low-intensity peak was found when BrdU was omitted altogether from the assay. In contrast, the gray bars represent cells that entered synthesis and incorporated some amount of BrdU.

It is interesting to note that exposure to a relatively high specific dose of $1.2 \times 10^{54}$ photon ${ }^{2} \mathrm{~cm}^{-4} \mathrm{~s}^{-1}$ in a single imaging plane within the RBL cell does not result in a substantial decrease in the percentage of cells undergoing synthesis. This dropped from a control level of $55 \pm 2 \%$ to only $50 \pm 3 \%$. Although this effect is slight, the histograms do show a redistribution of the mean nuclear fluorescence from $57.1 \pm 4.8$ to a significantly lower value of $33 \pm 3$. Thus, it appears that although the percentage of cells entering synthesis declined only slightly, DNA synthesis activity was significantly reduced. It is reasonable to assume that this reduction was because of sublethal photodamage caused by TPLSM, causing synthesis to be delayed until damage had been repaired. When the specific dose was reduced to $9.1 \times 10^{52}$ photon $^{2}$ $\mathrm{cm}^{-4} \mathrm{~s}^{-1}$, there was an insignificant change in either the percentage of cells entering synthesis or the mean nuclear fluorescence, indicating that no apparent damage resulted from TPLSM using this imaging protocol.

To verify that DNA synthesis was being delayed, a variable recovery period was added to the BrdU incorporation assay after imaging at a specific dose of $1.2 \times 10^{54}$ photon $^{2} \mathrm{~cm}^{-4} \mathrm{~s}^{-1}$, as shown schematically in Fig. 1. During this recovery period, both cells that had undergone TPLSM and control cells that were not irradiated but otherwise handled identically were placed in growth media in a $37^{\circ} \mathrm{C}$ incubator to allow additional time for repair

laser light. (B) RBL cells that have been exposed to a dose of $9.1 \times 10^{52}$ photon $\mathrm{cm}^{-4} \mathrm{~s}^{-1}$ (five images, $10 \mathrm{~mW}$ ). (C) RBL cells that have been exposed to a dose of $1.2 \times 10^{54}$ photon $\mathrm{cm}^{-4} \mathrm{~s}^{-1}$ (25 images, $\left.17 \mathrm{~mW}\right)$. 

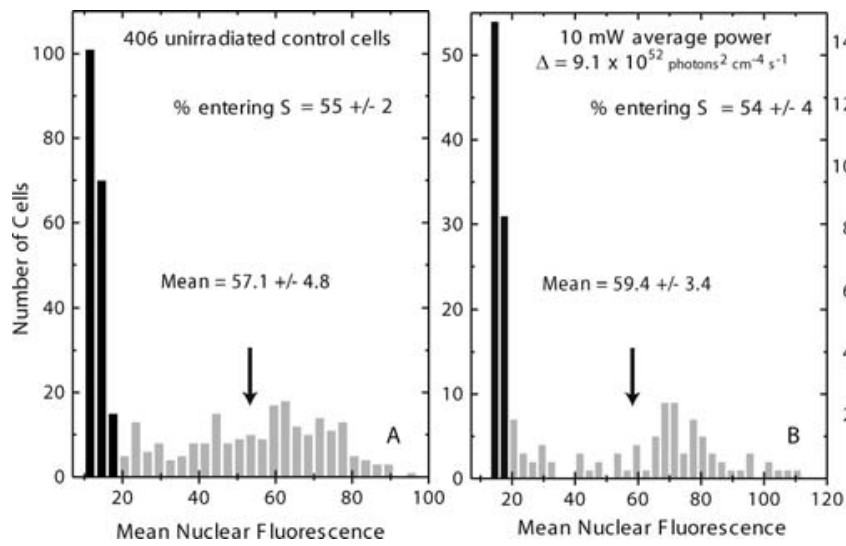

mechanisms to proceed before assaying DNA synthesis. Figure 7 shows that both the fraction of cells entering synthesis and the mean nuclear fluorescence increased as the recovery period was increased from 1 to $8 \mathrm{~h}$, with the biggest incremental improvement being between 4 and $8 \mathrm{~h}$. It is interesting to note that after an $8 \mathrm{~h}$ recovery period the fraction of cells entering synthesis after TPLSM consistently exceeded control levels.

Figures 8 and 9 summarize the effects of TPLSM on RBL cells imaged with specific doses ranging from $10^{52}$ to $10^{54}$ photon $^{2} \mathrm{~cm}^{-4}$ $\mathrm{s}^{-1}$ at $740 \mathrm{~nm}$ for imaging powers ranging from 5 to $17 \mathrm{~mW}$. Figure 8 shows that throughout the range of imaging conditions the fraction of cells entering synthesis remained fairly constant, regardless of the average power at the sample. From Fig. 9, we see that two-photon-specific doses less than approximately $2 \times 10^{53}$ photon $\mathrm{cm}^{-4} \mathrm{~s}^{-1}$ seemed to cause no significant change in the level of DNA synthesis in RBL cells when compared with controls.

\section{$\square$ Fluorescein-dUTP Intensity $\quad \square$ Fraction Entering Synthesis}

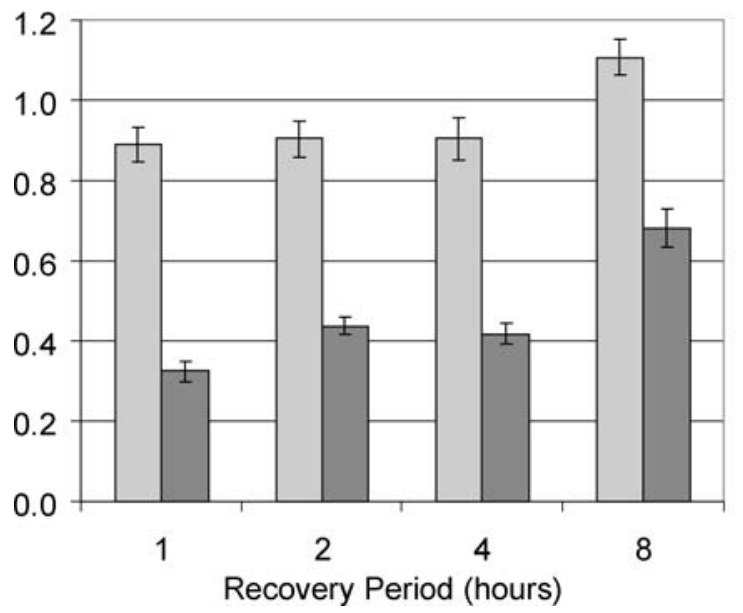

Figure 7. Effect of the length of the recovery period on BrdU incorporation by RBL cells after repetitive high-intensity $740 \mathrm{~nm}$ laser illumination. All cells received a two-photon dose of $1.2 \times 10^{54}$ photon $^{2}$ $\mathrm{cm}^{-4} \mathrm{~s}^{-1}$ (25 images at $17 \mathrm{~mW}$ ), but the recovery time interval was varied from 1 to $8 \mathrm{~h}$. Darker bars represent the mean nuclear fluorescence resulting from BrdU incorporation, whereas the lighter bars give the fraction of cells undergoing synthesis. Both are normalized to controls and are the weighted mean of three experiments, each consisting of five fields (total of approximately $400-600$ cells). The error bars represent the standard error in the weighted mean.

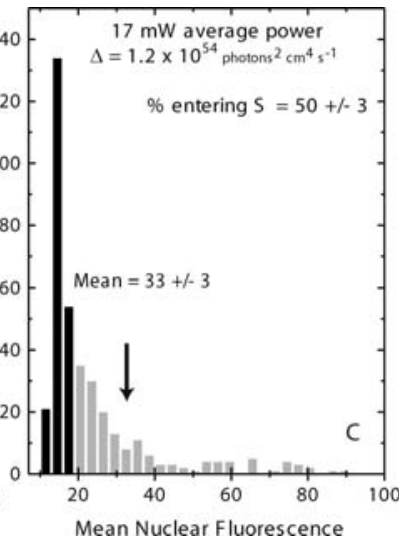

Figure 6. Histograms of the fluoresceindUTP-staining intensity for RBL cells similar to those shown in Fig. 5. (A) Histograms from unirradiated control cells. The black bars represent cells that did not enter DNA synthesis during the BrdU incorporation assay, whereas cells represented by gray bars had greater fluorescein-dUTP intensity than (-) BrdU controls. Cells that have been exposed to a dose of either (B) $9.1 \times$ $10^{52}$ photon $^{2} \mathrm{~cm}^{-4} \mathrm{~s}^{-1}$ or (C) $1.2 \times 10^{54}$ photon ${ }^{2} \mathrm{~cm}^{-4} \mathrm{~s}^{-1}$.
But beyond this dose, cells exposed to $17 \mathrm{~mW}$ average power clearly showed a decline in the mean nuclear fluorescence. When the dose exceeded $4 \times 10^{53}$ photon ${ }^{2} \mathrm{~cm}^{-4} \mathrm{~s}^{-1}$ from TPLSM at 17 $\mathrm{mW}, \mathrm{BrdU}$ incorporation was $40 \%$ of that of control cells, whereas TPLSM at $10 \mathrm{~mW}$ resulted in a higher level of approximately $60 \%$ of controls. Because of the sheer number of images required to exceed doses of $10^{54}$ photon ${ }^{2} \mathrm{~cm}^{-4} \mathrm{~s}^{-1}$ with $5 \mathrm{~mW}$ average power, it was not possible to achieve reasonable statistics within the confines of the irradiation protocol with this low average power. Nevertheless, at this dose, it appears that the normalized mean nuclear fluorescence was only slightly higher for cells exposed to 5 $\mathrm{mW}$ as compared with $10 \mathrm{~mW}$.

\section{DISCUSSION}

The BrdU incorporation assay used in this study is a sensitive indicator of sublethal damage. Studies of UV-C photodamage in RBL cells suggests that the sensitivity of the BrdU assay is approximately 330 times greater than the sensitivity of the calceinpropidium iodide "live-dead" assay, which determines a cell's status through a combination of loss of enzyme activity and membrane integrity (Nichols and coworkers, Photochem. Photo-

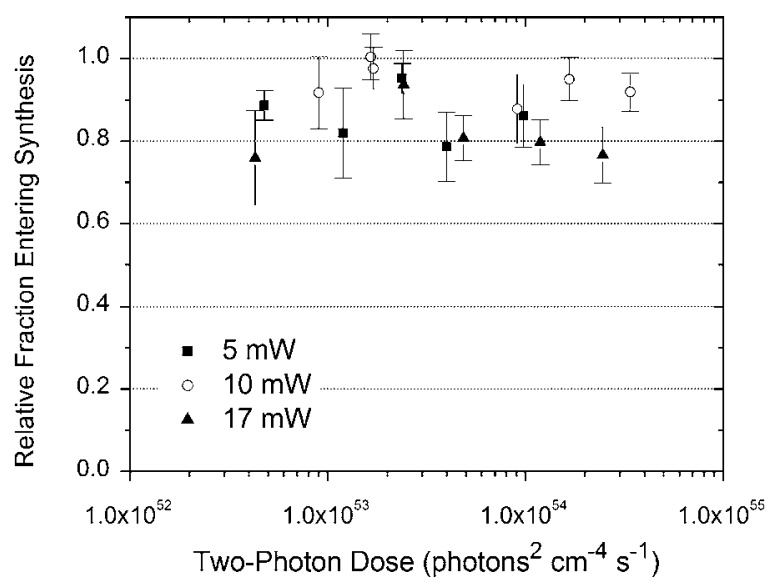

Figure 8. Relative fraction of cells entering synthesis during the BrdU incorporation assay. Any cell with mean nuclear fluorescence exceeding that of the (-) BrdU control group was counted as entering synthesis. Data points represent the mean values normalized to controls of several replicate experiments conducted at average powers of either $5 \mathrm{~mW}$ (square), $10 \mathrm{~mW}$ (circle) or $17 \mathrm{~mW}$ (triangle). The two-photon dose was calculated from the imaging conditions using Eq. 9 and Table 1. The error bars represent the standard error in the weighted mean. 


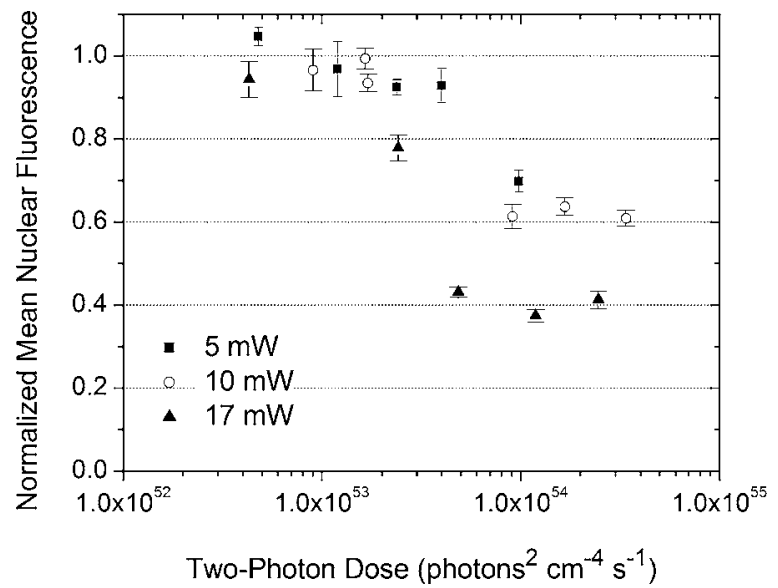

Figure 9. Fluorescein-dUTP-staining intensity of RBL cells after exposure to near-infrared imaging conditions at several two-photon doses. Data points represent the mean values normalized to controls of several replicate experiments, as described in Fig. 8. Error bars represent the standard error in the weighted mean.

bio., DOI: 10.1562/2004-08-04-RA-261). The calcein-propidium iodide assay, although useful for detecting lethal damage where morphological changes are plainly evident, proved incapable of measuring the onset of sublethal damage induced during TPLSM of $\mathrm{NAD}(\mathrm{P}) \mathrm{H}$ in this study. Throughout the range of imaging conditions used, cell morphology remained normal and cytotoxicity was extremely low.

There was no dose- or power-dependent change in the fraction of RBL cells entering synthesis for doses up to $4 \times 10^{54}$ photon $^{2}$ $\mathrm{cm}^{-4} \mathrm{~s}^{-1}(5-17 \mathrm{~mW})$ when the same focal plane was imaged repeatedly (Fig. 8). Yet, there did appear to be an intensitydependent reduction of DNA synthesis activity. The threshold for this effect was approximately $2 \times 10^{53}$ photon $^{2} \mathrm{~cm}^{-4} \mathrm{~s}^{-1}$. Increasing the dose beyond $4.8 \times 10^{53}$ photon $\mathrm{cm}^{-4} \mathrm{~s}^{-1}$ appeared to cause no additional reduction at average laser powers of either 10 or $17 \mathrm{~mW}$. This can be observed by comparing the nuclear fluorescence intensities for cells imaged at 10 and $17 \mathrm{~mW}$, which leveled off at $60 \%$ and $40 \%$ of that of controls, respectively (Fig. $9)$. RBL cells typically have a $25 \mathrm{~h}$ cell cycle. Allowing a recovery period of 4-8 h after imaging allowed damaged cells to continue traversing the cell cycle, as shown in Fig. 7. The observation that the percentage of damaged cells entering synthesis exceeded control levels after an $8 \mathrm{~h}$ delay suggests that there is some accumulation of damaged cells at a cell cycle control checkpoint, most likely at the G1/S border. Damaged cells that had not yet reached the G1/S checkpoint would continue cycling until they did, at which point they would arrest at the $S$ border until appropriate repair had taken place. This accumulation would result in a partial synchronization of cells that had been damaged, leading to an increase in cells undergoing synthesis when compared with unsynchronized controls. Additional experiments are needed to test this proposition.

We hypothesize that the extent of photodamage during TPLSM is limited by the characteristic localization of two-photon excitation to a small diffraction-limited focal volume. This is conceivable if oxidative stress is not only caused by photobleaching but also mitigated by bleaching of the multiphoton absorbers within the plane when resupply of these absorbers is slow relative to the imaging duration. Consider the observations shown in Fig. 3, in

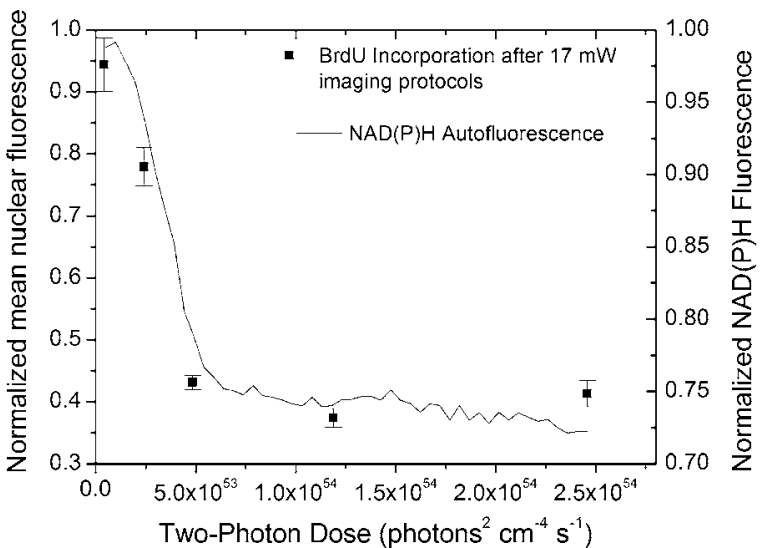

Figure 10. Comparison of the onset of damage after TPLSM of NAD(P)H with the observed loss of $\mathrm{NAD}(\mathrm{P}) \mathrm{H}$ fluorescence with specific dose. The data points are the same as those in Fig. 9 for an average power of $17 \mathrm{~mW}$, although dose is now shown on a linear scale. The line represents the average normalized $\mathrm{NAD}(\mathrm{P}) \mathrm{H}$ fluorescence intensity for several cells such as those shown in Fig. 3 .

which mitochondrial NAD(P)H fluorescence had been bleached away completely by the 11th image taken at $17 \mathrm{~mW}$ average power. If the principle source of damage originates from $\mathrm{NAD}(\mathrm{P}) \mathrm{H}$ photoproducts, then it follows that additional imaging would have limited consequence because the $\mathrm{NAD}(\mathrm{P}) \mathrm{H}$ has been depleted. This hypothesis is also consistent with our previous reports of DNA synthesis inhibition in HeLa cells (9). In that study, we found that distributing the dose throughout an entire HeLa cell caused the fraction of cells entering synthesis to decline significantly. By sequentially stepping the focus throughout the cell and imaging each plane, a greater supply of $\mathrm{NAD}(\mathrm{P}) \mathrm{H}$ would be available to produce the damaging photoproducts, which would result in greater DNA synthesis inhibition.

As illustrated in Fig. 10, there is an apparent correlation between the mitochondrial $\mathrm{NAD}(\mathrm{P}) \mathrm{H}$ fluorescence intensity and the DNA synthesis delay when imaging at high laser power. Once the mitochondrial $\mathrm{NAD}(\mathrm{P}) \mathrm{H}$ signal has decayed completely, additional imaging does not appear to lengthen the delay. Because the delay is longer (reduced nuclear fluorescence) for an equivalent specific dose delivered at a higher average power, this suggests that damage is being done faster than it can be repaired under these conditions. If it were possible to reduce the excitation rate, and hence the rate of damage, below the rate of repair, then one could image indefinitely with minimal cytotoxicity. Unfortunately, if the rate of damage occurs with the same intensity-squared dependence as the fluorescence emission rate, then the $\mathrm{NAD}(\mathrm{P}) \mathrm{H}$ signal would be lower as well. For TPLSM of NAD(P)H in RBL cells, $10 \mathrm{~mW}$ seems to be the lowest acceptable average power under our imaging conditions (Table 1) to adequately resolve the punctate mitochondrial fluorescence. Without changing some aspect of the imaging protocol, this places the number of images that can be acquired before the onset of DNA synthesis delay to be no greater than 15 .

Although it is possible to find prolonged imaging conditions under which $\mathrm{NAD}(\mathrm{P}) \mathrm{H}$ photobleaching is not discernable, this does not indicate that cellular damage is not occurring. In fact, a delay of synthesis was observed for average powers of 5 and $10 \mathrm{~mW}$ when the specific two-photon dose exceeded $2 \times 10^{53}$ photon $^{2} \mathrm{~cm}^{-4} \mathrm{~s}^{-1}$, although bleaching was not evident at this dose (as shown in Fig. 4). 
Because the concentration of $\mathrm{NAD}(\mathrm{P}) \mathrm{H}$ is actively regulated by the cell for efficient glycolysis and oxidative phosphorylation, it is likely that bleaching was actually occurring but not observable because of the cell's own regulation of these molecules. Careful inspection of the bleaching curves (as shown in Fig. 3C) revealed a small but reproducible initial plateau where the intrinsic cellular fluorescence remained unchanged for several images. After a threshold dose was exceeded, the cells could not compensate for the loss of $\mathrm{NAD}(\mathrm{P}) \mathrm{H}$ and bleaching was observed. Hence, it is likely that oxidative stress is occurring even when $\mathrm{NAD}(\mathrm{P}) \mathrm{H}$ fluorescence bleaching is not evident.

Once a sufficient dose was given to produce a noticeable decline in $\mathrm{NAD}(\mathrm{P}) \mathrm{H}$ fluorescence intensity, we did not observe a fluorescence recovery when scanning was paused for as long as $15 \mathrm{~min}$. Because photooxidation of NADH has been shown to result in enzymatically active $\mathrm{NAD}^{+}$, a fluorescence recovery was expected $(17,18)$. The lack of recovery may be attributed to free-radical damage of mitochondrial enzymes, but Joubert et al. (18) did not measure a loss of enzyme activity in mitochondrial extracts that had been preilluminated by UV light. Another possibility, more consistent with the findings of that report, would be the formation of irreversible NADH products resulting from extensive freeradical damage.

The observed reduction in DNA synthesis is a result of sublethal damage that can occur during two-photon metabolic imaging. It is important to recognize that there is a regimen of average powers ranging from 10 to $17 \mathrm{~mW}$ that appears to be "safe," provided the specific dose is kept below a threshold value. These results may appear to be in conflict with several other reports that show lethal damage resulting from TPLSM using average powers lower than $10 \mathrm{~mW}$ at similar wavelengths. If one considers the total dose instead of the average power, these results can be reconciled.

During intrinsic fluorescence imaging of $\mathrm{CHO}$ cells, König et al. (26) reported that average powers above $6 \mathrm{~mW}$ at $730 \mathrm{~nm}$ (and 7 $\mathrm{mW}$ at $760 \mathrm{~nm}$ ) produced lethal damage. Although we did not observe anything approaching that degree of damage in this study, even with average laser powers of $17 \mathrm{~mW}$, there are some essential differences between this study and theirs. In this study, an image was produced by averaging three consecutive frames, using a beam-scan rate of approximately $29.4 \mu \mathrm{m} / \mathrm{ms}$. From the information provided in König et al. (26), their beam-scan rate was 17 times slower, only $1.71 \mu \mathrm{m} / \mathrm{ms}$. Provided that the repetition rate, power and pulse width of the lasers were comparable, the slower scan rate would result in a much greater cellular dose. In fact, we have observed the onset of the extremely bright and broadband fluorescence, as reported by König et al. (26), when we park the laser beam in a perinuclear region of the cell for fraction of a second (27). It should be expected that the increased dwell time may in fact permit distinctly different photodamage mechanisms that do not occur when the dwell time is decreased.

More recently, König et al. (28) reported a loss of cell viability (as measured by calcein-ethidium homodimer-1) in nonlabeled $\mathrm{CHO}$ cells at powers as low as $7.3 \mathrm{~mW}$ using $240 \mathrm{fs}, 780 \mathrm{~nm}$ laser pulses. In that study, the dwell time of the beam within a $\mathrm{CHO}$ cell was reported to be $400 \mathrm{~ms}$ per scan. In contrast, the imaging protocols used in this study resulted in a dwell time of only $13 \mathrm{~ms}$ per image (three scans) in the RBL cells, which have a cross-sectional area of approximately $230 \mu^{2}$, three-fold lower than that reported for $\mathrm{CHO}$ cells. Similar to the reduced scan rate, the larger dwell time within the cell provides a greater dose for the same laser power.
Tirlapur et al. (8) have reported evidence indicating that TPLSM at $800 \mathrm{~nm}$ caused apoptosis in PtK2 cells when average powers exceeded $7 \mathrm{~mW}$. Using a similar TdT end-labeling assay, we were unable to find any evidence for induction of apoptosis in RBL cells by TPLSM for laser powers ranging from 5 to $17 \mathrm{~mW}$ at $740 \mathrm{~nm}$. This is interesting given the evidence leading one to expect photodamage to decrease substantially as the laser wavelength is increased in this range. Although it should also be anticipated that different cell lines will have a different sensitivity to near-infrared radiation, it is clear that a simple comparison based on laser power alone is insufficient to set a "safe imaging" window for multiphoton microscopy.

We have made the assumption in this study that the delivered dose is proportional to the number of two-photon-absorption events. Additional experiments measuring the reduction of DNA synthesis activity as a function of the laser pulse width are needed to confirm this assumption and will be the subject of a future article. Nevertheless, this assumption is supported by König et al. (28), who reported a power-squared dependence on $\mathrm{CHO}$ cell proliferation at 780 and $920 \mathrm{~nm}$, and also by Koester et al. (29), who reported an exponent of $2.00 \pm 0.38$ at $870 \mathrm{~nm}$. More recently, Hopt and Neher (30) have reported changes in the resting calcium level in bovine adrenal chromaffin cells during two-photon imaging of calcium with FURA-2-AM. They also report morphological changes consistent with degranulation that scaled with the intensity raised to a power of $2.43 \pm 0.1$, when the average laser power was varied from 20 to $50 \mathrm{~mW}$ at 840 $\mathrm{nm}$, and extrapolated from their data a safe working power of 2.5 $\mathrm{mW}$. It is important to recognize that because this is a large extrapolation, damage may not be proportional to the intensity with an exponent of 2.43 at lower, more relevant, imaging powers. If damage results from a mixture of two- and threephoton processes, then the two-photon process would be favored as the power is decreased, as the authors acknowledge. Hence, the recommended safe imaging power of $2.5 \mathrm{~mW}$, on the basis of the assumption that damage increases with an intensity exponent of 2.5 , is questionable.

On the basis of the variety of safe imaging powers reported in the multiphoton literature and the data presented in this study, we conclude that the notion of a safe imaging power is fundamentally misleading. In the same report proposing a safe imaging power, Hopt and Neher (30) provided data indicating that damage is, in fact, proportional to the beam dwell time within the cell. A safe, or threshold, imaging power implies that photodamage would be independent of the dwell time, provided this threshold is not exceeded. In the literature to date, no such threshold power has been demonstrated. The data presented in this study demonstrates that a more relevant concept for quantifying photodamage in multiphoton microscopy is a threshold dose. This should not be surprising because the concept of a threshold dose has been well established in the analysis of survival curves of mammalian cells exposed to a variety of cytotoxic agents, including ionizing and nonionizing radiations.

\section{CONCLUSIONS}

In conclusion, photodamage resulting from TPLSM of NAD $(\mathrm{P}) \mathrm{H}$ fluorescence in RBL cells may correlate with the observed twophoton bleaching of $\mathrm{NAD}(\mathrm{P}) \mathrm{H}$ at high power but not at low power. We hypothesize that this discrepancy is attributed to the regulation 
of $\mathrm{NAD}(\mathrm{P}) \mathrm{H}$ within the cell, which is sufficient to accommodate losses because of bleaching at low power but not at high power. The damage resulting from two-photon-specific doses as high as $10^{54}$ photon $^{2} \mathrm{~cm}^{-4} \mathrm{~s}^{-1}$ (50 images at $17 \mathrm{~mW}$ ) was apparent as a subtle reduction in DNA synthesis, without obvious changes in cell morphology. By allowing an $8 \mathrm{~h}$ recovery period after imaging, the level of DNA synthesis was observed to return to control levels. When a single plane was scanned repetitively, the reduction in DNA synthesis appeared to level off, consistent with the inherent localization of multiphoton excitation. By quantifying the exposure of the RBL cells to intense near-infrared radiation during TPLSM as a proper two-photon dose, we have attempted to account for all the relevant imaging parameters that contribute to photodamage. Although other reports have been published that indicate the average power must be reduced below a minimum value for safe TPLSM, it is important to realize that other aspects of the imaging process, such as the dwell time within the cell and the inherent sensitivity of the cell itself, will also affect the degree of photodamage at any power. For metabolic imaging of $\mathrm{NAD}(\mathrm{P}) \mathrm{H}$ in RBL cells, we find that it is possible to image with average powers in the range of $10-17 \mathrm{~mW}$, provided the specific dose is kept below a threshold value of $2 \times 10^{53}$ photon $^{2} \mathrm{~cm}^{-4} \mathrm{~s}^{-1}$.

The two-photon dose to an individual cell will necessarily vary according to the number of two-photon absorbers within the cell in the plane of focus, as shown by (Eq. 4). By measuring the reduction in DNA synthesis as a function of the incident twophoton-specific dose $(\Delta)$, we have made the reasonable assumption that any given cell contains the same average number of absorbing molecules. In addition, it is reasonable to expect that there may be a variety of biological responses associated with TPLSM of individual subcellular compartments such as the nucleus, cytoplasm and specific organelles. Experiments using laser scanning microscopy to identify and irradiate specific subcellular compartments in a field of cells are needed to fully characterize the photophysical mechanism leading to biological responses such as the observed reduction in DNA synthesis reported in this study.

Acknowledgements-This study was conducted at the Developmental Resource for Biophysical Imaging and Opto-electronics (DRBIO) at Cornell University while M.G.N. was an NIH NRSA fellow (F32 CA 72225). DRBIO was supported by the NIH (RR04224) and NSF (BIR 8800278). The authors express their gratitude to Watt Webb and Warren Zipfel for many helpful discussions and to Sam Hess for his calculation of the twophoton point-spread function. This publication was supported by revenue from the Nebraska Tobacco Settlement awarded to Creighton University by the State of Nebraska. Its contents are solely the responsibility of the authors and do not necessarily represent the official views of the State of Nebraska.

\section{REFERENCES}

1. Denk, W. and K. Svobada (1997) Photon upmanship: why multiphoton imaging is more than a gimmick. Neuron 18, 351-357.

2. Xu, C., W. Zipfel, J. B. Shear, R. M. Williams and W. W. Webb (1996) Multiphoton fluorescence excitation: new spectral windows for biological nonlinear microscopy. Proc. Natl. Acad. Sci. USA 93, 10763 10768.

3. White, J. G., J. M. Squirrell and K. W. Eliceiri (2001) Applying multiphoton imaging to the study of membrane dynamics in living cells. Traffic 2, 775-780.

4. Mohanty, S. K., A. Rapp, S. Monajembashi, P. K. Gupta and K. O. Greulich (2002) Comet assay measurements of DNA damage in cells by laser microbeams and trapping beams with wavelengths spanning a range of $308 \mathrm{~nm}$ to $1064 \mathrm{~nm}$. Radiat. Res. 157, 378-385.
5. Hockberger, P. E., T. A. Skimina, V. E. Centonze, C. Lavin, S. Chu, S. Dadras, J. K. Reddy and J. G. White (1999) Activation of flavincontaining oxidases underlies light-induced production of $\mathrm{H}_{2} \mathrm{O}_{2}$ in mammalian cells. Proc. Natl. Acad. Sci. USA 96, 6255-6260.

6. Squirrell, J. M., D. L. Wokosin, J. G. White and B. D. Bavister (1999) Long-term two-photon fluorescence imaging of mammalian embryos without compromising viability. Nat. Biotechnol. 17, 763-767.

7. Oehring, H., I. Riemann, P. Fisher, K.-J. Halbhuber and K. König (2000) Ultrastructure and reproduction behavior of single CHO-K1 cells exposed to near infrared femtosecond laser pulses. Scanning 22, 263-270.

8. Tirlapur, U. K., K. König, C. Peuckert, R. Krieg and K. Halbhuber (2001) Femtosecond near-infrared laser pulses elicit generation of reactive oxygen species in mammalian cells leading to apoptosis-like death. Exp. Cell Res. 263, 88-97.

9. Nichols, J. A. and W. W. Webb (1998) Multiphoton microscopy: a tool to study photodamage. Biophys. J. 74, A189.

10. Nichols, M. G., J. A. Nichols and W. W. Webb (1999) Visualization of mitochondria via two-photon-excited NADH fluorescence: identifying conditions that maintain cell viability. Biophys. J. 76, A9.

11. Kasischke, K. A., H. D. Vishwasrao, P. J. Fisher, W. R. Zipfel and W. W. Webb (2004) Neural activity triggers neuronal oxidative metabolism followed by astrocytic glycolysis. Science 305, 99-103.

12. Bennett, B. D., T. L. Jetton, G. Ying, M. A. Magnuson and D. W. Piston (1996) Quantitative subcellular imaging of glucose metabolism with intact pancreatic islets. J. Biol. Chem. 271, 3647-3651.

13. Piston, D. W., B. R. Masters and W. W. Webb (1995) Three dimensionally resolved $\mathrm{NAD}(\mathrm{P}) \mathrm{H}$ cellular metabolic redox imaging of the in situ cornea with two-photon excitation laser scanning microscopy. J. Microsc. 178, 20-27.

14. Blinova, K., C. Combs, P. Kellman and R. S. Balaban (2004) Fluctuation analysis of NADH fluorescence signals in confocal and two-photon microscopy images of living cardiac myocytes. J. Microsc. 213, 70-75.

15. Indig, G. L., G. S. Anderson, M. G. Nichols, J. A. Bartlett, W. S. Mellon and F. Sieber (2000) Effect of molecular structure on the performance of triarylmethane dyes as therapeutic agents for photochemical purging of autologous bone marrow grafts from residual tumor cells. J. Pharm. Sci. 89, 88-99.

16. Nichols, M. G. and W. W. Webb (1998) Simultaneous imaging of Photofrin and NADH autofluorescence in cell monolayers and multicell tumor spheroids. Photochem. Photobiol. 67S, 95S.

17. Czochralska, B., W. Kawczynski, G. Bartosz and D. Shugar (1984) Oxidation of excited-state NADH and NAD dimer in aqueous medium involvement of $\mathrm{O}_{2}^{-}$as a mediator in the presence of oxygen. Biochim. Biophys. Acta 801, 403-409.

18. Joubert, F., H. M. Fales, H. Wen, C. A. Combs and R. S. Balaban (2004) NADH enzyme-dependent fluorescence recovery after photobleaching: applications to enzyme and mitochondrial reactions kinetics, in vitro. Biophys. J. 86, 629-645.

19. Xu, C. and W. W. Webb (1997) Multiphoton excitation of molecular fluorophores and nonlinear laser microscopy. In Topics in Fluorescence Spectroscopy, Volume 5: Nonlinear and Two-Photon Induced Fluorescence. (Edited by J. Lakowicz), pp. 471-540. Plenum Press, New York.

20. Guild, J. B., C. Xu and W. W. Webb (1997) Measurement of group delay dispersion of high numerical aperture objective lenses using twophoton excited fluorescence. Appl. Opt. 36, 397-401.

21. Hess, S. T. and W. W. Webb (2002) Focal volume optics and experimental artifacts in confocal fluorescence correlation spectroscopy. Biophys. J. 83, 2300-2317.

22. Richards, B. and E. Wolf (1959) Electromagnetic diffraction in optical systems. II. Structure of the image field in an aplantic system. Proc. $R$. Soc. Lond. A 253, 358-379.

23. Li, X., F. Traganos, M. R. Melamed and Z. Darzynkiewicz (1985) Single-step procedure for labeling DNA strand breaks with fluoresceinor BODIPY-conjugated deoxynucleotides: detection of apoptosis and bromodeoxyuridine incorporation. Cytometry 20, 172-180.

24. Shafirovich, V., A. Dourandin, N. P. Luneva, C. Singh, F. Kirigin and N. E. Geacintov (1999) Multiphoton near-infrared femtosecond laser pulse-induced DNA damage with and without the photosensitizer proflavine. Photochem. Photobiol. 69, 265-274.

25. Bevington, P. R. and D. K. Robinson (1992) Data Reduction and Error Analysis for the Physical Sciences, 2nd ed. McGraw-Hill, New York.

26. König, K., P. T. C. So, W. W. Mantulin, B. J. Tromberg and E. Gratton (1996) Two-photon excited lifetime imaging of autofluorescence in 
cells during UVA exposure and NIR photostress. J. Microsc. 183, 197-204.

27. Nichols, M. G. and W. W. Webb (1996) Identification of the principle sources of two-photon autofluorescence from HeLa cell monolayers. Biophys. J. 72, A346.

28. König, K., T. W. Becker, P. Fischer, I. Riemann and K.-J. Halbhuber (1999) Pulse-length dependence of cellular response to intense near- infrared laser pulses in multiphoton microscopes. Opt. Lett. 24, 113115.

29. Koester, H. J., D. Baur, R. Uhl and S. W. Hell (1999) $\mathrm{Ca}^{2+}$ fluorescence imaging with pico- and femtosecond two-photon excitation: signal and photodamage. Biophys. J. 77, 2226-2236.

30. Hopt, A. and E. Neher (2001) Highly nonlinear photodamage in twophoton fluorescence microscopy. Biophys. J. 80, 2029-2036. 